\section{(6) OPEN ACCESS}

\title{
My approach to water-assisted colonoscopy
}

\author{
Keith Siau, ${ }^{1,2}$ Iosif Beintaris ${ }^{3}$
}

${ }^{1}$ Department of

Gastroenterology, Dudley Group Hospitals NHS Foundation Trust, Dudley, UK

${ }^{2}$ Medical and Dental Sciences, University of Birmingham,

Birmingham, UK ${ }^{3}$ Department of

Gastroenterology, North Tees and Hartlepool NHS Foundation Trust, Stockton-on-Tees, UK

\section{Correspondence to}

Dr Keith Siau, Dudley Group Hospitals NHS Foundation Trust, Dudley DY12HQ, UK; keith@ siau.org

Received 9 November 2018 Revised 3 December 2018 Accepted 9 December 2018 Published Online First 22 December 2018

\section{Check for updates}

(C) Author(s) (or their employer(s)) 2019. Re-use permitted under CC BY-NC. No commercial reuse. See rights and permissions. Published by BMJ.

To cite: Siau K, Beintaris I. Frontline Gastroenterology 2019;10:194-197.

\begin{abstract}
The goal of diagnostic colonoscopy is to achieve procedural completion while maximising effectiveness, patient acceptance and safety. In recent years, international interest in waterassisted colonoscopy (WAC) has been steadily gathering pace. A plethora of high-quality randomised controlled trials and meta-analyses now offer incontrovertible evidence into the benefits of WAC, both for the endoscopist and the patient. Despite this, uptake of WAC within the UK has been limited, with the lack of educational resources representing a significant barrier. This practical step-by-step guide is aimed at both existing practitioners and trainees, with a view to promoting familiarity with WAC and potentially for incorporation into daily practice which may ultimately have a positive effect on quality of colonoscopy and patient experience.
\end{abstract}

\section{BACKGROUND}

In recent years, interest in water-assisted colonoscopy (WAC) has been gathering pace, spurred by the explosion of highquality studies which now offer incontrovertible evidence into the benefits of WAC to both the endoscopist and the patient. ${ }^{1-6}$ The benefits of WAC arise from two principal mechanisms: (1) use of water exerts a gravitational effect and reduces colonic elongation, thereby reducing loop formation, procedure discomfort and sedation requirements, ${ }^{7}$ (2) water irrigation improves mucosal views and can increase adenoma detection rates (ADR). ${ }^{146}$ The learning curve is relatively short; WAC may be grasped by existing practitioners after 50 procedures $^{5}$ and can expedite competency acquisition in novice trainees. ${ }^{8}$ Despite this, uptake of WAC within the UK has been limited, with the lack of educational resources representing a potential barrier. Herein, we provide a pragmatic guide which could be used by endoscopists to implement WAC into their daily practice, with the aim to ultimately improve quality of colonoscopy.

\section{DEFINITIONS}

WAC is a colonoscopy procedure which uses water as the main insufflation method. WAC encompasses:

a. Water immersion (WI): insufflation with water and suction of luminal air on intubation. On withdrawal, water is suctioned and air/ $/ \mathrm{CO}_{2}$ insufflation used as per standard practice.

b. Water exchange (WE): simultaneous water infusion and suction of air and dirty (opaque) luminal contents during insertion, until distention with transparent water is achieved. This is the gold standard WAC technique, as supported by literature to date.

c. Modified/limited WAC, for example, confined to the left colon.

d. Total WAC: entire procedure performed with water only.

\section{PREPARATION}

\section{Online resources}

Before trialling WAC, readers should review the following online resources: (1) an illustrated guide on the effect of water on colonic anatomy, ${ }^{9}$ and (2) a video demonstration by Cadoni and Ishaq. ${ }^{10}$

\section{Equipment}

WAC can be performed using pre-existing colonoscopes and equipment, with the addition of a standard irrigation pump. A dedicated water channel is desirable but not essential as it facilitates WE by enabling the simultaneous infusion of clean water and suctioning of 'dirty' fluid. For colonoscopes without this feature, irrigation may be connected to the suction port, but this precludes simultaneous infusion and suction. Irrigation tubing is connected to a standard $1 \mathrm{~L}$ bottle containing water between room and body temperature. ${ }^{11}$ Air within the irrigation system should be expunged during testing.

The water pump rate should be adjusted according to technique; those who 
perform simultaneous infusion and suction should maximise infusion rates to deliver net positive water balance.

Attachment of a distal transparent cap may reduce caecal intubation times by minimising mucosal suctioning and red-outs, ${ }^{12}$ but can also reduce field of view. Other attachments, for example, Endocuff, have not been studied in WAC.

For beginners, we recommend switching off $\mathrm{CO}_{2}$ once endoscope function is checked. Subconscious or overzealous $\mathrm{CO}_{2}$ insufflation can obviate the benefits of WAC in loop/angulation formation and cause discomfort.

\section{Consent}

Eighty per cent of our WAC procedures are performed unsedated with or without the use of nitrous oxide. The technique does not confer additional procedural risk. Patients should be consented for a standard colonoscopy. For uncomplicated patients desiring sedation, we discuss the benefits of unsedated WAC. Most patients do agree to forgo sedation, with 95\% of patients willing to undergo repeat unsedated WAC after the procedure. ${ }^{4}$

\section{Planning}

Standard preprocedural preparations apply, including review of indications, contraindications and previous endoscopic or radiological investigations. Enquiring about compliance and efficacy of bowel preparation may indicate whether WE/colonoscopy is feasible. Preprocedure checklists reduce error rates and should be completed. As with all endoscopic procedures, background music may help. ${ }^{13}$

\section{Positioning}

Starting the procedure in the left lateral position is beneficial as the gravitational effect of infused water pools in the sigmoid-descending colon and tends to straighten the rectosigmoid junction. ${ }^{7}$ Line the bed with disposable waterproof pads in case of water leakage. Ergonomically, it is optimal to position the foot pump to the left of the endoscopist. It is advisable to assign one foot for the foot pump (eg, left foot) and the other for diathermy pedals. The bed should be positioned at waist height and the monitor within optimal distance. ${ }^{14}$

\section{INSERTION}

\section{General principles}

Prior to insertion, apply ample lubrication to the anal canal and colonoscope. Advance the colonoscope approximately $2-3 \mathrm{~cm}$ through the rectal ampulla, as water insufflation distal to this can lead to anal leakage. Position the colonoscope tip centrally within the lumen and gently infuse water. Pause to assess the quality of bowel preparation. WE should be first line: infuse water, either in pulses (IB) or continuously (KS) and apply concomitant suction to clear gas pockets and opaque water until a clear view is obtained. Direct the water jet to wash off coated mucosa. If visibility is poor despite patience with initiating WE (20-30s), switch to WI or $\mathrm{CO}_{2}$ insufflation (if solid stools) until mucosal views improve.

Suctioning is an important skill and should be applied to pockets of air and residual stool (WE). Beginners may be frustrated with inadvertent suctioning of the mucosa. This can be minimised by slightly deflecting the tip to the 11 o'clock position (opposite the typical five o'clock position of the suction channel) before suctioning, ${ }^{10}$ or by using a cap.

Advance the colonoscope gently while applying principles of loop prevention, that is, frequent withdrawals with to-and-fro motions to keep the colonoscope straight, avoid excessive tip angulation, apply torque and ensure one-to-one movement. If resistance is encountered, check the magnetic endoscope imager or scope distance for looping, pull back and reconsider a different approach. Torque should be reapplied on intubation and abdominal pressure or position change considered to avoid loop recurrence. It may be necessary to resolve and externalise loops.

If polyps are detected, consider marking them, for example, applying suction mark, biopsy or tattoo. Alternatively, for minute lesions, resect during intubation (KS) to avoid missing them on withdrawal.

Converse with the patient. In addition to providing distraction and information on WAC, patients may disseminate positive experiences and drive engagement with colonoscopy.

\section{Distal colon}

At the distal colon, similar principles to standard colonoscopy apply, but with emphasis on water infusion, scope-tip positioning and suctioning. There should be net water infused at the rectosigmoid junction (KS: $200 \mathrm{~mL}+$ ) to allow the gravity of water to straighten the rectosigmoid bend and minimise looping.

Hysterectomy and diverticular segments may pose a challenge. Occasionally, the lumen may fail to distend with water; limited bursts of $\mathrm{CO}_{2}$ may be required to identify the lumen. Dedicate up to $50 \%$ of the insertion time towards negotiating the distal colon.

\section{Transverse colon}

Proactively turning the patient to the supine position at the splenic flexure allows redistribution of water down the transverse colon. Use of the stiffener, diaphragmatic splinting with deep inhalation, or sigmoid pressure may assist colonoscope advancement.

In the case of suboptimal bowel preparation or time constraints, consider switching to WI or $\mathrm{CO}_{2}$ insufflation. Use of WI minimises proximal colonic distention and transverse loop formation. At the mid-tranverse colon, anticlockwise torque may be required. It may be prudent to reapply externalised loops back into the colon. 


\section{Proximal colon}

The textbook position for entering the hepatic flexure is the left lateral position. ${ }^{15}$ Once traversed, perform judicious WE at the caecal pole as this is a high-risk area for missed pathology. Begin suctioning; consider adding simethicone to the water bottle if bubbles persist. Identify the caecal landmarks and photodocument the appendiceal orifice, caecal pole and the ileocaecal valve. ${ }^{16}$ It is advisable to turn to the right lateral position to improve caecal views. This also facilitates terminal ileum (TI) intubation which should be performed routinely (KS). The endoscopist may be guided by the ileocaecal valve and the appendiceal 'bow-and-arrow sign'. ${ }^{15}$ Position the ileocaecal valve at nine o'clock (or six o'clock), slowly withdraw the tip back from the appendix, decompress the caecum and apply anticlockwise torque and left wheel angulation to slip into the TI. WI can accentuate the ileal villi for inspection and photodocumentation. ${ }^{17}$ On exiting the TI, commence the withdrawal timer.

\section{WITHDRAWAL}

Hyoscine (Buscopan) may improve ADR, but lacks evidence in WAC. The blind spot between the appendiceal orifice and ileocaecal valve should be inspected. Caecal retroversion increases polyp yield and should be attempted. ${ }^{18}$ At the ileocaecal valve, advance the scope, maximise angulation with both wheels before pulling back. Once the retroverted view is seen, pull back towards the hepatic flexure. With the patient in the right lateral position, re-advance the scope to the caecal pole for a second look in a different position. ${ }^{19}$

On withdrawal, ensure adherence to the $\geq 6 \mathrm{~min}$ (ideally $\geq 10 \mathrm{~min}$ ) withdrawal time. ${ }^{16}$ The cleaner views afforded by WE will minimise the need for washing mucosa, allowing focus on polyp detection. ${ }^{20}$ Nevertheless, all residual faecal coating should be washed which may uncover sessile serrated lesions.

Ensure colonic insufflation with $\mathrm{CO}_{2}$ and suctioning of contents after completing each segment. Rectal retroflexion should be performed. ${ }^{18}$

In addition to standard components of report writing, use of the WI/WE method and the volume of fluid suctioned should be stated.

\section{WATER-ASSISTED POLYPECTOMY}

Water-assisted polypectomy (WAP) is safe and effective, ${ }^{21}$ obviating the need for submucosal resection. Detailed discussion is beyond the scope of this article. WAP is especially useful for pedunculated polyps, where water can lift a polyp head over the snare and aid positioning, but also aids piecemeal procedures, allowing remnant polyp tissue to float and facilitate tissue grasping with the snare.

\section{FAILED PROCEDURES}

Several considerations may help in the case of completion failure:
1. Change endoscope: a paediatric colonoscope or gastroscope may allow negotiation of a fixed pelvis with adhesions.

2. Consider more water: enhanced gravitational effect.

3. Consider reinsertion in an alternate position, for example, right lateral/prone, along with using targeted external pressure as directed by the magnetic endoscope imager where available.

4. Optimise sedation and consider rescheduling under a more experienced endoscopist and/or propofol list.

\section{SUMMARY}

WAC can be performed by existing colonoscopists using standard equipment but requires motivation and modification of existing technique. ${ }^{20}$ Water insufflation can hamper luminal views on intubation and requires precise suctioning technique and tip control fluency. For beginners, efforts at WE, higher rates of adenoma yield and subsequent polypectomy will impact on procedure time; this improves once competency is achieved. ${ }^{2}$ A recent meta-analysis showed that WE was associated with an average additional procedure time of $1.8 \mathrm{~min}^{3}$ In return, WAC can reduce loop formation and procedural discomfort, mitigate sedation-related risks, improve mucosal views and ADR, and increase overall patient satisfaction. For endoscopists who are willing to adapt their technique, WAC can be feasibly implemented to improve overall quality of colonoscopy and patient experience.

Twitter KS: @drkeithsiau; IB: @iosifbeintaris

Contributors KS conceived the article and drafted the original manuscript. IB provided critical review, ensured the validity of the described techniques and enhanced the quality of the manuscript.

Competing interests $\mathrm{KS}$ and IB have been commissioned by Springer to write a textbook on water-assisted colonoscopy. IB is a co-investigator for the UK Water Assisted Sigmoidoscopy (WASh) trial.

Patient consent Not required.

Provenance and peer review Not commissioned; externally peer reviewed.

Open access This is an open access article distributed in accordance with the Creative Commons Attribution Non Commercial (CC BY-NC 4.0) license, which permits others to distribute, remix, adapt, build upon this work noncommercially, and license their derivative works on different terms, provided the original work is properly cited, appropriate credit is given, any changes made indicated, and the use is noncommercial. See: http://creativecommons.org/licenses/by-nc/4. $0 /$.

\section{REFERENCES}

1 Fuccio L, Frazzoni L, Hassan C, et al. Water exchange colonoscopy increases adenoma detection rate: a systematic review with network meta-analysis of randomized controlled studies. Gastrointest Endosc 2018;88:589-97.

2 Cadoni S, Falt P, Gallittu P, et al. Water exchange is the least painful colonoscope insertion technique and increases completion of unsedated colonoscopy. Clin Gastroenterol Hepatol 2015;13:1972-80.

3 Cadoni S, Hassan C, Frazzoni L, et al. Impact of water exchange colonoscopy on endoscopy room efficiency: a 
systematic review and meta-analysis. Gastrointest Endosc 2018:32861-X.

4 Jia H, Pan Y, Guo X, et al. Water exchange method significantly improves adenoma detection rate: a multicenter, randomized controlled trial. Am J Gastroenterol 2017;112:568-76.

5 Azevedo R, Leitão C, Pinto J, et al. Can water exchange improve patient tolerance in unsedated colonoscopy a prospective comparative study. GE Port J Gastroenterol 2018;25:166-74.

6 Hafner S, Zolk K, Radaelli F, et al. Water infusion versus air insufflation for colonoscopy. Cochrane Database Syst Rev 2015:CD009863.

7 Asai S, Fujimoto N, Tanoue K, et al. Water immersion colonoscopy facilitates straight passage of the colonoscope through the sigmoid colon without loop formation: randomized controlled trial. Dig Endosc 2015;27:345-53.

8 Siau K, Hawkes ND, Dunckley P. Training in endoscopy. Curr Treat Options Gastroenterol 2018;16:345-61.

9 Colon Explorer. The Water Immersion Technique for Colonoscopy Insertion. 2018 http://www.endoscopy-colonexplorer.com/the-water-immersion-technique-for-colonoscopyinsertion/ (cited 5th Nov 2018).

10 Cadoni S, Ishaq S. How to perform water-aided colonoscopy, with differences between water immersion and water exchange: a teaching video demonstration. VideoGIE 2018;3:169-70.

11 Falt P, Šmajstrla V, Fojtík P, et al. Cool water vs warm water immersion for minimal sedation colonoscopy: a double-blind randomized trial. Colorectal Dis 2013;15:e612-7.

12 Tseng CW, Koo M, Hsieh YH. Cecal intubation time between cap-assisted water exchange and water exchange colonoscopy: a randomized-controlled trial. Eur J Gastroenterol Hepatol 2017;29:1296-302.

13 Wang MC, Zhang LY, Zhang YL, et al. Effect of music in endoscopy procedures: systematic review and metaanalysis of randomized controlled trials. Pain Med 2014;15:1786-94.

14 Segal JP, Kanagasundaram C, Mills P, et al. Polyp detection rate: does length matter? Frontline Gastroenterol 2019;10:107-12.

15 Waye JD, Thomas-Gibson S. How I do colonoscopy. Gastrointest Endosc 2018;87:621-4.

16 Rees CJ, Thomas Gibson S, Rutter MD, et al. UK key performance indicators and quality assurance standards for colonoscopy. Gut 2016;65:1923-9.

17 Powell N. The use of cecal and terminal lleal images for verifying the completion of colonoscopy. Gastroenterol Hepatol 2011;7:536-9.

18 Rex DK, Vemulapalli KC. Retroflexion in colonoscopy: why? where? when? how? what value? Gastroenterology 2013;144:882-3.

19 Clark BT, Parikh ND, Laine L. Yield of repeat forwardview examination of the right side of the colon in screening and surveillance colonoscopy. Gastrointest Endosc 2016;84:126-32.

20 Siau K, Cadoni S. Colonoscope insertion: is the future underwater. GE Port J Gastroenterol 2018;25:163-5.

21 Siau K, Ishaq S, Cadoni S, et al. Feasibility and outcomes of underwater endoscopic mucosal resection for $\geq 10 \mathrm{~mm}$ colorectal polyps. Surg Endosc 2018;32:2656-63. 